\title{
NON INVASIVE PREDICTORS OF CORONARY SLOW FLOW
}

\author{
Ragab AbdelSalam Mahfouz, Mesbah Taha Hasanein, Elsayed Mohamad Farag, Radwa Mohamad \\ Abdullah* \\ Cardiology Department, Faculty of Medicine, Zagazig University.
} \begin{abstract}
distal vessel opacification in the absence of significant epicardial coronary stenosis. The pathogenic mechanisms are incompletely understood. It has direct clinical implications, being linked to clinical manifestations of myocardial ischemia, life-threatening arrhythmias, sudden cardiac death, and recurrent acute coronary syndrome.

Aim of the work: To evaluate the role of non-invasive measures in predicting Primary coronary slow flow patients.

Patients and methods: Our study was a case control study, taking patients referred for cardiac catheterization for suspected coronary artery disease. We took two groups 50 patients each.Group I: primary coronary slow flow phenomenon. Group II: normal coronary angiography. All patients were subjected to thorough clinical examination and full lab including lipid panel, hsCRP and Troponin, ECG where PWD and QTc dispersion were measured, TTE including coronary flow velocities (Diastolic and systolic) and DSPVR (Diastolic and systolic peak velocity ratio) as well as assessment of TIMI frame counts.

Results: The independent factors predicting PCSF among the examined groups, included diabetes, P wave dispersion $\geq 60$ msec, QT dispersion $\geq 60 \mathrm{msec}$, HCT (hemataocrit) level $\geq 40 \%$ and hs CRP $\geq 4 \mathrm{mg} / \mathrm{L}$ and DSPVR $\leq 1.6$. A score was done for the independent variables using the prediction equation for multiple regression. Patients with scores $>12$ are more likely to have PCSF $(\mathrm{P}=0.000)$.

Conclusion: PCSF is associated with diabetes, greater PWD and QTc dispersion, higher HCT and hsCRP levels.

Key words: Primary coronary slow flow, Non invasive procedures.
\end{abstract}

\section{INTRODUCTION}

T he coronary slow flow phenomenon (CSFP) is an angiographic clinical entity, characterized by delayed distal vessel opacification in the absence of significant epicardial coronary stenosis. (Wang $X$ and Nie S, 2011)

The overall incidence of CSFP is $1 \%$ among patients who undergo coronary angiography, especially those presenting with acute coronary syndrome. (Chaudhry M. et al, 2012)

Several hypotheses of its mechanism including a form of early phase of atherosclerosis, microvessel dysfunction, Hagen-Poiseuille's equation model, imbalance between vasoconstrictor and vasodilatory factors, and platelet function disorder were proposed. (Sadamatsu K et al, 2007).

This condition, which may affect one or all coronaries, was originally described by Tambe et al. in 1972. Since then it has been accepted as an independent clinical entity, which is called 'CSFP', 'coronary slow flow syndrome' 'syndrome Y', or "primary" coronary slow flow (Wang $X$ and Nie $S$, 2011).

A number of case series have subsequently been published and have consistently shown the phenomenon to occur in a unique demographic group (Turner $S, 2006$ ). Patients with the CSFP are characterized by: Preponderance of middle aged males, Most have mixed pattern angina, Ongoing chest pain symptoms despite treatment with many undergoing repeat invasive and non invasive investigations (Turner $S$, 2006).

Despite good prognosis of CSFP patients, the subsequent progress is frequently characterized by remitting, relapsing anginal episodes resulting in considerable impairment in quality of life (Wang $X$ and Nie S, 2011).

There is no definite treatment for patients with CSFP. Nitrates have been reported to be ineffective. By contrast dipyridamole seems to be effective in an acute setting during coronary angiography in patients with CSFP (Paul L et al, 2007).

There is no substantial data regarding the use of conventional calcium L-channel blockers such as amlodipine in patients with CSFP (Chaudhry M. et al, 2012).

Beltrame et al. assessed the acute and longterm clinical benefits of mibefradil in patients with CSFP. There was a significant acute angiographic improvement in coronary flow indices. Long term clinical benefits with mibefradil were also observed (Paul L et al, 2007).

\section{AIM OF THE WORK}

To evaluate the role of non-invasive measures in predicting Primary coronary slow flow patients.

\section{PATIENTS AND METHODS}

We conducted a case-control study using two groups: Group I: 50 patients with primary coronary slow flow phenomenon. Group II: 50 patients with normal coronary angiography .The 
study was done in Zagazig - University Hospitals' catheterization laboratories during the period from May 2011 to December 2013.

\section{Inclusion criteria:}

Patients referred for coronary angiography because of suspected coronary artery disease.

\section{Exclusion criteria:}

Coronary artery stenosis, Coronary vasospasm, Coronary ectasia, Uncontrolled hypertension and severe LVH, Atrial fibrillation and cardiac rhythm other than sinus, Angiography and stenting of acute myocardial infarction, Heart failure and cardiomyopathy, Valvular heart disease, Connective tissue disease, Tachycardia, anaemia and thyrotoxicosis, Malignancy. Renal and hepatic dysfunction, Acute and chronic infection. Current use of anti-inflammatory drugs.

\section{All patients were subjected to:}

1- Request to sign a consent form.

2- Thorough history taking and physical examination.

3- Height and weight were measured using a standardized protocol. BMI (Body mass index) was calculated by dividing weight in kilograms by height in meters squared.

4- Laboratory parameters including were collected from the patients after a 12 hours overnight fasting and done at Zagazig University hospitals clinical pathology laboratories:

- Complete blood picture including mean platelet volume, white blood cell count and hematocrit using Sysmex KX 21 system.

- HA1c by Cobas 6000 plus system (Roche, USA) after an overnight fasting.

- Complete lipid panel by Cobas Integra 400 plus system (Roche, USA).

- Kidney function tests including serum creatinine by Cobas Integra 400 plus system (Roche, USA).

- Cardiac troponin T by Cobas 6000 plus system (Roche, USA).

- High sensitive CRP by Cobas Integra 400 plus system (Roche, USA).

5- Two 12 lead-ECGs were obtained for each patient at rest: one standard and the second with 20 $\mathrm{mm} / \mathrm{mV}$ amplitude and $50 \mathrm{~mm} / \mathrm{sec}$ rate with standard lead positions.

The ECGs were manually assessed measuring the maximum $\boldsymbol{P}$ wave duration (the beginning of the $\mathrm{P}$ wave was defined as the point where the initial deflection of the $p$ wave crossed the isoelectric line, and the end of the $\mathrm{P}$ wave was defined as the point where the final deflection of the
$\mathrm{P}$ wave crossed the isoelectric line), $\boldsymbol{P}$ wave dispersion (the difference between maximum and minimum $\mathrm{P}$ wave duration) and QTc dispersion (the difference between the longest (QTc max) and the shortest (QTc min) QT intervals within a 12-lead ECG).(Gunes Y et al, 2009).

6- Transthoracic echocardiography and color Doppler:

The echocardiographic examination was performed at rest with a Kontron medical and a Hewlett Packard (Sonos 5000) ultrasound units using S3, S4 and S8 transducers.

Echocardiographic images were obtained from the acoustic windows around MCL in the $4^{\text {th }}$ and $5^{\text {th }}$ intercostal spaces in left lateral decubitus. Left ventricle is adequately visualized in all subjects. Once a two chamber view was obtained the high frequency transducer was superimposed over the same point on the thoracic surface, and a modified foreshortened 2- Chamber view was obtained by sliding the transducer superiorly and medially.

The epicardial segment of the anterior wall was focalized to find and best visualize the colorcoded blood flow in the anterior groove area. In case of scarce visualization from the apical view, a short axis view of the left ventricular apex and of the anterior groove was obtained, trying to visualize the coronary flow with color Doppler. Once a good color-coded Doppler was obtained, pulsed wave Doppler was attempted using a gate size set at 4.0 $\mathrm{mm}$. attention was paid to maintain the angle between the color flow and the Doppler beam below $20^{\circ}$.

Echocardiographic measurements:

a- Left ventricular end systolic and diastolic dimensions (LVEDD, LVESD).

b- Left ventricular systolic function ( LVEF).

c- Left atrial diameter.

d- E, A and E/A ratio.

e- Coronary flow velocity: Diastolic and systolic peak velocities and DSPVR was calculated.

7- Coronary angiography was performed in Zagazig University Hospitals Catheterization laboratories (Cine angiographic equipment :Philips Integris: cine frame: $30 \mathrm{fps}$ ). Selective coronary angiography with standard multi-angulated angiographic views was performed through the femoral artery under local anesthesia (2\% Lidocaine) using the Judkins catheters and iopromide (Ultravist) as the contrast agent. The angiograms were recorded on a compact disc in DICOM format. 
Coronary blood flow was measured quantitatively using the TIMI frame count which was derived from the number of cine- frames recorded from the first entrance of contrast to its arrival at the distal end of the left anterior descending artery, circumflex artery, or right coronary artery. The last frames used for the LAD, CX and RCA were those in which the dye first

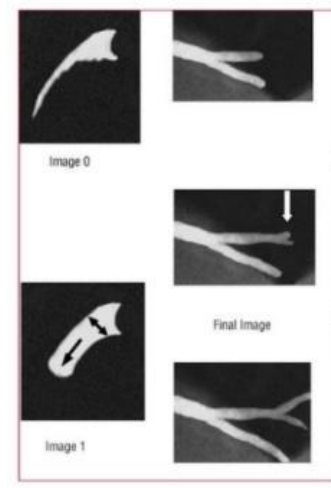

Figure (1): Calculating TIMI frame counts. The first counting frame (frame 1) is the image where the contrast advances and fills at least $70 \%$ of the diameter of the arterial ostium. The last frame (final frame) is the image where the contrast begins to fill the final landmark. Distal bifurcations of the 3 epicardial arteries are shown. CD indicates right coronary artery; $\mathrm{Cx}$, circumflex artery; DA, left anterior descending coronary artery. (Gibson $\boldsymbol{C}$ et al, 2005)

Statistical analysis:

- All statistical data were processed using the IBM SPSS 19 software. Data were expressed as mean \pm standard deviation (SD). Student t-test, and chi-square test were used to compare the variables. Correlations between the TIMI frame counts and other parameters were analyzed. A stepwise multivariate analysis was done for independent variables. Odds ratios and $95 \%$ confidence intervals were also calculated. A P value of less than 0.05 was considered significant. A PCSF score was done using the prediction equation for multiple regression.

\section{RESULTS}

Our study is a case control study. We took two groups: Group I: 50 patients with primary entered the mustache segment, the distal bifurcation segment and first branch of the posterolateral artery, respectively.The TIMI frame count of the LAD artery was corrected by dividing the final count by 1.7.The cut-off values were defined according to the TIMI frame count method of Gibson et al. $(36 \pm 2.6$ for $\mathrm{LAD}, 22.2 \pm 4.1$ for $\mathrm{Cx}, 20.4 \pm 3.0$ for RCA).

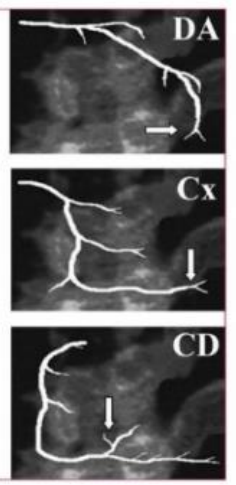

coronary slow flow (PCSF) and Group II: 50 Patients with normal Coronary angiography. Patients with PCSF phenomenon showed increased incidence of diabetes. (35 patients $70 \%$ ) compared to (24 patients $48 \%$ in the control group, $\mathrm{P}=0.025$ ). As regards to smoking the number of smokers in the PCSF group were (30 patients $60 \%$ ) compared to 11 patients in the control group, $\mathrm{P}<0.0001)$. Patients with PSCF had higher CCSA. Table (1).

Patients in the PCSF group had higher P max, P wave dispersion, QTc $\min$ and QTc dispersion compared to the control group with $\mathrm{P}$ value $s(0.01,0.0001,0.001$ and 0.002 respectively. Regarding echo parameter PCSF group patients had greater LA diameter, and showed increased both diastolic and systolic peak flow velocities of the LAD compared to the control group with $\mathrm{P}$ values $(0.03,0.000$ and 0.000 respectively). Yet regarding the DSPVR it was lower in patients with PCSF compared to the control group with very high statistical significant difference $(\mathrm{P}$ value $=0.000)$. Table (2).

Patients with PCSF had higher WBCs count, HCT, MPV and HsCRP compared to those in the control group, with very high statistical significant difference $(\mathrm{P}<0.0001)$. 
Table (1): Demographic data, risk factors and clinical data of both groups:

\begin{tabular}{|c|c|c|c|c|c|}
\hline & $\begin{array}{c}\text { PCSF } \\
50 \text { patients } \\
\end{array}$ & $\begin{array}{c}\text { Control } \\
50 \text { patients }\end{array}$ & Test & $\begin{array}{c}\text { Test } \\
\text { value }\end{array}$ & $\mathbf{P}$ \\
\hline $\begin{array}{l}\text { Age in years } \\
(\chi \pm \text { SD }) \\
\end{array}$ & $49.56 \pm 7.8$ & $52.3 \pm 7.9$ & $\mathbf{t}$ & 1.76 & 0.08 \\
\hline $\begin{array}{cc}\text { Sex } & \\
\text { M } & \text { n (\%) } \\
\text { F } & \text { n }(\%) \\
\end{array}$ & $\begin{array}{l}34(68 \%) \\
16(32 \%) \\
\end{array}$ & $\begin{array}{l}26(52 \%) \\
24(48 \%) \\
\end{array}$ & $\chi^{2}$ & 2.67 & 0.1 \\
\hline $\begin{array}{l}\text { BMI } \\
(\chi \pm \text { SD }) \\
\end{array}$ & $30.48 \pm 5.36$ & $30,16 \pm 3.2$ & $\mathbf{t}$ & 0.36 & 0.71 \\
\hline HTN & $21(42 \%)$ & $29(58 \%)$ & $\chi^{2}$ & 2.56 & 0.11 \\
\hline DM & $35(70 \%)$ & $24(48 \%)$ & $\chi^{2}$ & 5 & $0.025 *$ \\
\hline Smoking & $30(60 \%)$ & $11(22 \%)$ & $\chi^{2}$ & 14.9 & $<0.0001 * *$ \\
\hline $\begin{array}{l}\text { HR bpm } \\
(\chi \pm \text { SD }) \\
\end{array}$ & $76.04 \pm 10.71$ & $78.42 \pm 10.4$ & $\mathbf{t}$ & 1.12 & 0.26 \\
\hline $\begin{array}{l}\text { SBP mmHg } \\
(\chi \pm \text { SD })\end{array}$ & $121.6 \pm 12.39$ & $121.5 \pm 13.4$ & $\mathbf{t}$ & 0.04 & 0.96 \\
\hline $\begin{array}{l}\text { DBP mmHg } \\
(\chi \pm \text { SD })\end{array}$ & $78 \pm 8.08$ & $79.4 \pm 9.67$ & $\mathbf{t}$ & 0.7 & 0.43 \\
\hline $\begin{array}{l}\text { CCSA } \\
\mathbf{N}(\%) \\
\text { Class } 2 \\
\text { Class } 3 \\
\text { Class } 4\end{array}$ & $\begin{array}{l}11(22 \%) \\
20(40 \%) \\
19(38 \%)\end{array}$ & $\begin{array}{c}20(40 \%) \\
30(60 \%) \\
0(0 \%)\end{array}$ & $\chi^{2}$ & 23.25 & $\begin{array}{c}0.052 \\
\mathbf{0 . 0 4}^{*} \\
<\mathbf{0 . 0 0 0 1} * *\end{array}$ \\
\hline
\end{tabular}

$\mathbf{P C S F}=$ Primary coronary slow flow; $\mathrm{M}=$ Male, $\mathrm{F}=$ female, $\mathrm{BMI}=$ body mass index, HTN= Hypertension, $\mathrm{DM}=$ diabetes, $\chi=$ mean, * statistically significant, $* *=$ very high statistical significance, $H R=$ heart rate in beats per minute, $\mathrm{SBP}=$ systolic blood pressure, $\mathrm{DBP}=$ diastolic blood pressure, CCSA class= Canadian cardiovascular society class.

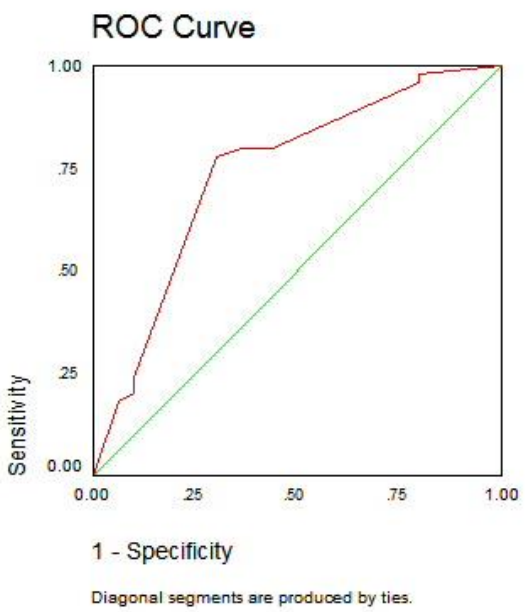

Figure (2): ROC curve for PWD showing sensitivity of $78 \%$ and specificity of $70 \%$ at a cut off value at 60 msec (AUC at $95 \% \mathrm{CI}=0.74(0.64-0.84)$ ) 
Table (2): ECG and ECHO data of both groups:

\begin{tabular}{|c|c|c|c|c|}
\hline & $\begin{array}{c}\text { PCSF } \\
50 \text { patients }\end{array}$ & $\begin{array}{c}\text { Control } \\
50 \text { patients }\end{array}$ & T test & $P$ value \\
\hline $\begin{array}{l}\text { P max msec } \\
(\chi \pm \text { SD })\end{array}$ & $124.04 \pm 16.15$ & $108.6 \pm 27.18$ & 3.45 & $0.01 *$ \\
\hline $\begin{array}{l}P \text { min msec } \\
(\chi \pm S D)\end{array}$ & $62.4 \pm 13.97$ & $64.52 \pm 20.04$ & 0.6 & 0.54 \\
\hline $\begin{array}{l}\text { PWd msec } \\
(\chi \pm \text { SD }) \\
\end{array}$ & $59.44 \pm 13.95$ & $45.68 \pm 17.34$ & 4.37 & $<0.0001 * *$ \\
\hline $\begin{array}{l}\text { QTc max msec } \\
(\chi \pm \text { SD })\end{array}$ & $467.28 \pm 35.97$ & $462.82 \pm 24$ & 0.73 & 0.46 \\
\hline $\begin{array}{l}\text { QTc min msec } \\
(\chi \pm \text { SD })\end{array}$ & $377.2 \pm 31.69$ & $397 \pm 30.19$ & 3.29 & $0.001 * *$ \\
\hline $\begin{array}{l}\text { QTed msec } \\
(\chi \pm \text { SD })\end{array}$ & $90.08 \pm 39.82$ & $67.92 \pm 27.01$ & 3.26 & $0.002 *$ \\
\hline $\begin{array}{l}\text { LVEDD in } \mathrm{mm} \\
(\chi \pm \text { SD })\end{array}$ & $49.24 \pm 4.28$ & $48.9 \pm 4.53$ & 0.39 & 0.7 \\
\hline $\begin{array}{l}\text { LVESD in mm } \\
(\chi \pm \text { SD })\end{array}$ & $27.54 \pm 5.49$ & $28.18 \pm 4.62$ & 0.63 & 0.53 \\
\hline $\begin{array}{l}\text { LVEF \% } \\
(\chi \pm \text { SD) }\end{array}$ & $68 \pm 6.27$ & $66.9 \pm 7.22$ & 0.8 & 0.41 \\
\hline $\begin{array}{l}\text { E/A ratio } \\
(\chi \pm \text { SD) }\end{array}$ & $0.805 \pm 0.1$ & $0.78 \pm 0.1$ & 1.23 & 0.22 \\
\hline $\begin{array}{l}\text { LA in } \mathbf{~ m m} \\
(\chi \pm \text { SD })\end{array}$ & $36.46 \pm 3.86$ & $34.56 \pm 4.95$ & 2.14 & $\mathbf{0 . 0 3} *$ \\
\hline $\begin{array}{l}\text { SPV of LAD } \\
\mathrm{Mm} / \mathrm{sec} \\
(\chi \pm \mathrm{SD})\end{array}$ & $21.28 \pm 4.3$ & $41.68 \pm 4.75$ & 22.5 & $0.000 * *$ \\
\hline $\begin{array}{l}\text { DPV of LAD } \\
\text { Mm/sec } \\
(\chi \pm \text { SD })\end{array}$ & $41.34 \pm 4.43$ & $57.48 \pm 5.55$ & 16.1 & $0.000 * *$ \\
\hline $\begin{array}{l}\text { DSPVR } \\
(\chi \pm \text { SD }) \\
\end{array}$ & $1.92 \pm 0.27$ & $1.39 \pm 0.11$ & 12.5 & $0.000 * *$ \\
\hline
\end{tabular}

PWd = P wave dispersion, QTc= corrected QT interval, QTed = corrected QT dispersion, LVEDD: Left ventricular end diastolic dimension.

LVESD: Left ventricular end systolic dimensioin, LVEF: Left ventricular ejection fraction, SPV: systolic peak velocity, DPV: Diastilic peak

velocity, DSPVR: Diastolic systolic peak velocity ratio 
Table (3): Laboratory data of both groups:

$\begin{array}{cccc}\text { PCSF } & \text { Control } & \text { T test } & \text { P value } \\ \text { 50 patients } & \text { 50 patients } & & \end{array}$

\begin{tabular}{|c|c|c|c|c|}
\hline $\begin{array}{l}\text { TC } \\
(\chi \pm \text { SD })\end{array}$ & $203.56 \pm 31.56$ & $200.12 \pm 34.11$ & 0.5 & 0.6 \\
\hline $\begin{array}{l}\text { TG } \\
(\chi \pm S D)\end{array}$ & $100.4 \pm 18.3$ & $97.58 \pm 14.66$ & 0.85 & 0.39 \\
\hline $\begin{array}{l}\text { LDL } \\
(\chi \pm \text { SD })\end{array}$ & $137.86 \pm 29.5$ & $130.86 \pm 22.39$ & 1.34 & 0.18 \\
\hline $\begin{array}{l}\text { HDL } \\
(\chi \pm \text { SD })\end{array}$ & $42.34 \pm 3.09$ & $41.04 \pm 3.73$ & 1.89 & 0.61 \\
\hline $\begin{array}{l}\text { WBC } \\
(\chi \pm \text { SD })\end{array}$ & $8.84 \pm 1.82$ & $6.21 \pm 1.32$ & 8.27 & $<0.0001 * *$ \\
\hline $\begin{array}{l}\text { HGB } \\
(\chi \pm \text { SD })\end{array}$ & $12.89 \pm 0.78$ & $12.65 \pm 0.92$ & 1.39 & 0.17 \\
\hline $\begin{array}{l}\text { HCT } \\
(\chi \pm \text { SD })\end{array}$ & $41.96 \pm 3.8$ & $39.48 \pm 1.78$ & 4.19 & $<0.0001 * *$ \\
\hline $\begin{array}{l}\text { PLT } \\
(\chi \pm \text { SD })\end{array}$ & $260.78 \pm 30.1$ & $267.72 \pm 44.96$ & 0.9 & 0.36 \\
\hline $\begin{array}{l}\text { MPV } \\
(\chi \pm \text { SD })\end{array}$ & $9.91 \pm 1.55$ & $7.41 \pm 0.5$ & 10.8 & $<0.0001 * *$ \\
\hline $\begin{array}{l}\text { HsCRP } \\
(\chi \pm \text { SD }) \\
\end{array}$ & $7.77 \pm 1.89$ & $3.56 \pm 1.29$ & 13.1 & $<0.0001 * *$ \\
\hline $\begin{array}{l}\text { S.Cr. } \\
(\chi \pm \text { SD })\end{array}$ & $0.9 \pm 0.156$ & $0.914 \pm 0.23$ & 0.2 & 0.84 \\
\hline $\begin{array}{l}\text { Tn } \\
(\chi \pm \text { SD })\end{array}$ & $0.14 \pm 0.35$ & $0.01 \pm 0.2$ & 1.7 & 0.82 \\
\hline $\begin{array}{l}\text { HbA1C } \\
(\chi \pm \text { SD })\end{array}$ & $6.64 \pm 1.43$ & $6.05 \pm 2.01$ & 1.7 & 0.098 \\
\hline
\end{tabular}

TC: Total cholesterol, TG: Triglycerides, LDL: Low density lipoprotein, HDL: High density lipoprotein, WBC: White blood cells.
HGB:Haemoglobin, HCT: Haematocrit, PLT: Platelets, MPV: Mean platelet volume, HsCRP: High sensitivity $\mathrm{C}$ reactive protein.

S.Cr. : Serum creatinine, Tn: Troponin, HbA1C: Haemoglobin A1C.

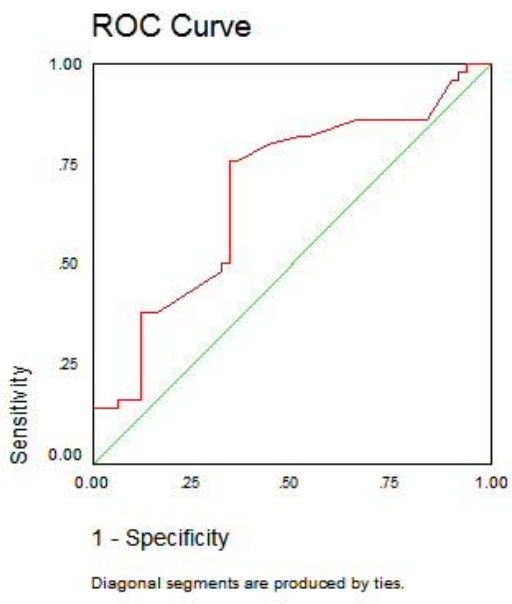

Figure (3): ROC curve for QTcd showing sensitivity of $76 \%$ and specificity of $64 \%$ at a cut off value of60 msec. $($ AUC at $95 \% \mathrm{CI}=0.68(0.57-0.78)$ ). 


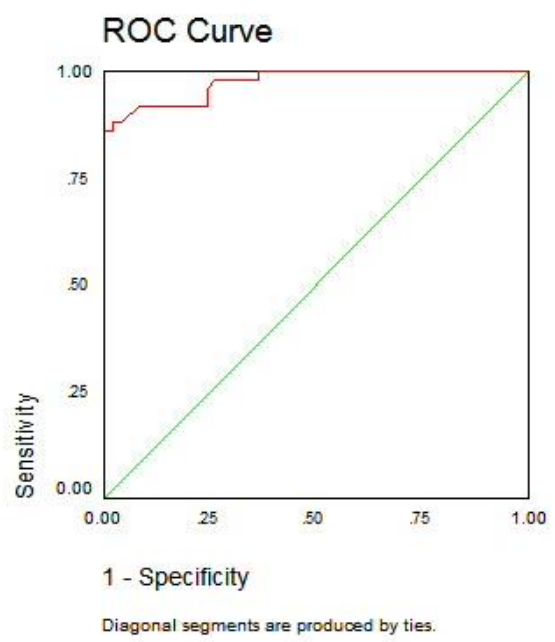

Figure(4): ROC curve for DSPVR showing sensitivity of $78 \%$ and specificity of $92 \%$ at a cut off value of $\leq$ 1.6 (AUC at $95 \% \mathrm{CI}=0.97(0.95-1.0)$.

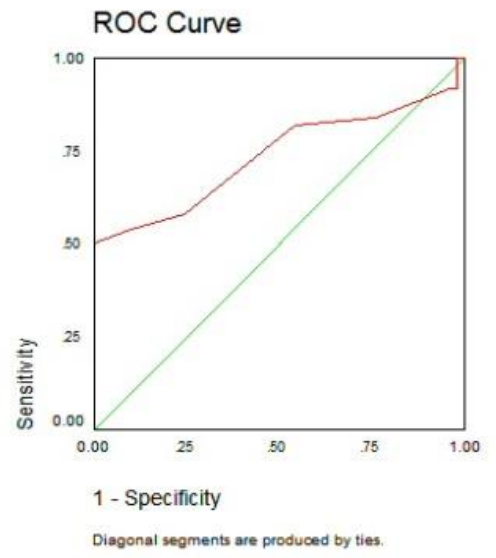

Figure (5):ROC curve for HCT showing sensitivity of $82 \%$ and specificity of $46 \%$ at a cut off value of 40 ( AUC at $95 \% \mathrm{CI}=0.73(0.63-0.84))$.

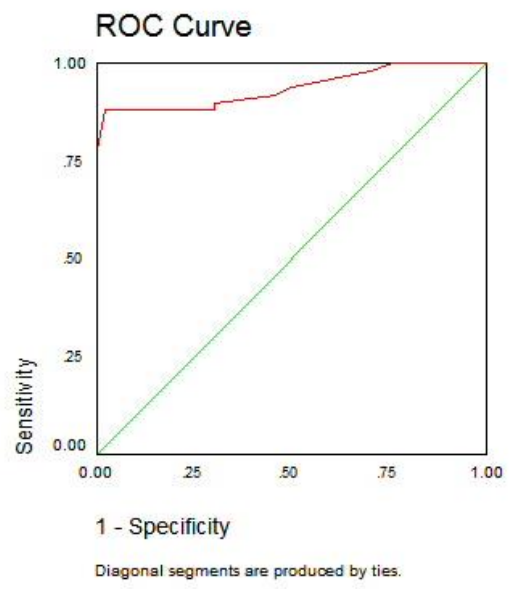

Figure(6): ROC curve for HsCRP showing sensitivity of $90 \%$ and specificity of $70 \%$ at a cut off value of 4 (AUC at $95 \% \mathrm{CI}=0.93(0.88-0.98)$ ).

\section{Stepwise multivariate analysis}


Table (4): Stepwise regression analysis of factors predicting PCSF

\begin{tabular}{lccccc}
\hline & $\boldsymbol{\beta}$ & S.E. & Wald & P Value & Exp (B) (95\% CI) \\
\hline DM & 2.6 & 1.03 & 6.29 & 0.01 & $13.46(1.76-102.67)$ \\
\hline PWD60 & 2.17 & 0.99 & 4.81 & 0.02 & $8.79(1.26-61.38)$ \\
\hline QTed60 & 2.922 & 1.0 & 8.54 & 0.003 & $18.5(2.61-131.81)$ \\
\hline HT40 & 3.188 & 1.118 & 8.12 & 0.004 & $24.24(2.71-217.08)$ \\
\hline hSCRP4 & 2.018 & 1.216 & 2.57 & 0.09 & $7.52(0.69-81.466)$ \\
\hline DSPVR $\leq 1.6$ & 3.262 & 1.126 & 8.38 & 0.004 & $26.11(2.87-237.4)$ \\
\hline \multicolumn{1}{c}{ Constant } & -9.809 & 2.51 & 15.24 & 0.000 & \\
\hline
\end{tabular}

$\mathrm{OR}=$ odds ratio.

$\mathrm{CI}=$ Confidence interval.

Logistic regression analysis of factors predicting PCSF among the examined groups, included diabetes, $\mathrm{P}$ wave dispersion at $60 \mathrm{msec}$, QTc dispersion at $60 \mathrm{msec}$, hemataocrit level at 40 $\%$ and $\mathrm{hsCRP}$ at $4 \mathrm{mg} / \mathrm{L}$ and $\mathrm{DSPVR} \leq 1.6$.

Diabetic patients were 13.46 times at risk of having PCSF by angiography than non diabetics.

Patients with $\mathrm{P}$ wave dispersion $\geq$ $60 \mathrm{msec}$ were 8.79 times likely to have PCSF.

Patients with QTc dispersion $\geq 60$ msec were 18.5 times to have PCSF than those with lower levels of QTc dispersion.
Patients with hematocrit level of $\geq$ $40 \%$ were 24.2 times more prone to have PCSF by coronary angiography than those with lower levels.

Patients with hsCRP $\geq 4 \mathrm{mg} / \mathrm{L}$ werer 7.5 times more likely to have PCSF by angiography than those with lower levels of hs CRP.

Patients with DSPVR $\leq 1.6$ were 26.11 times more likely to have PCSF by angiography than those with higher DSPV ratios. Scoring for PCSF phenomenon was done using the independent variables.

Table (5): Scoring for PCSF phenomenon

\begin{tabular}{ll}
\hline DM & \\
No & 0 \\
Yes & 1 \\
\hline PWD & 1 \\
$<60$ msec. & 2 \\
$\geq 60$ mse & 1 \\
\hline QTd & 2 \\
$<60$ msec & \\
$\geq 60$ msec & 1 \\
\hline HT & 2 \\
$<40$ & \\
$\geq 40$ & 1 \\
\hline HsCRP & 2 \\
$<4$ & \\
$\geq 4$ & 1 \\
\hline DSPVR & 2 \\
$>1.6$ & 2 \\
$\leq 1.6$ & \\
\hline
\end{tabular}

The PCSF score was calculated for each individual using the independent variables by the prediction equation for multiple regression (Munro B, 2001):

$$
Y=\alpha+\beta 1 \chi 1+\beta 2 \chi 2+\beta 3 \chi 3+\beta 4 \chi 4+\beta 5 \chi 5+\beta 6 \chi 6
$$

Where $\alpha$ is the intercept constant and equals -9.405

$\mathrm{B}$ : is the seperable weight for each of the independent variables. 
$\mathrm{B} 1$ for diabetes $=2.6$

B2 for PWD60 $=2.175$

$\mathrm{B} 3$ for QTd60 $=2.922$

B4 for $\mathrm{HT} 40=3.188$

$\mathrm{B} 5$ for $\mathrm{HsCRP} 4=2.018$

B6 for DSPVR $\leq 1.6=3.262$

Scoring was done for each patient in both groups using the equation giving values ranging from 2.75 to 20.92. A cut off value $\geq 12$ was selected to identify patients with PCSF and ROC curve for that cut off value showed sensitivity of $96 \%$, specificity of $70 \%$.

Table (6): The validilty of cut off value of $>=12$ in prediction of PCSFP

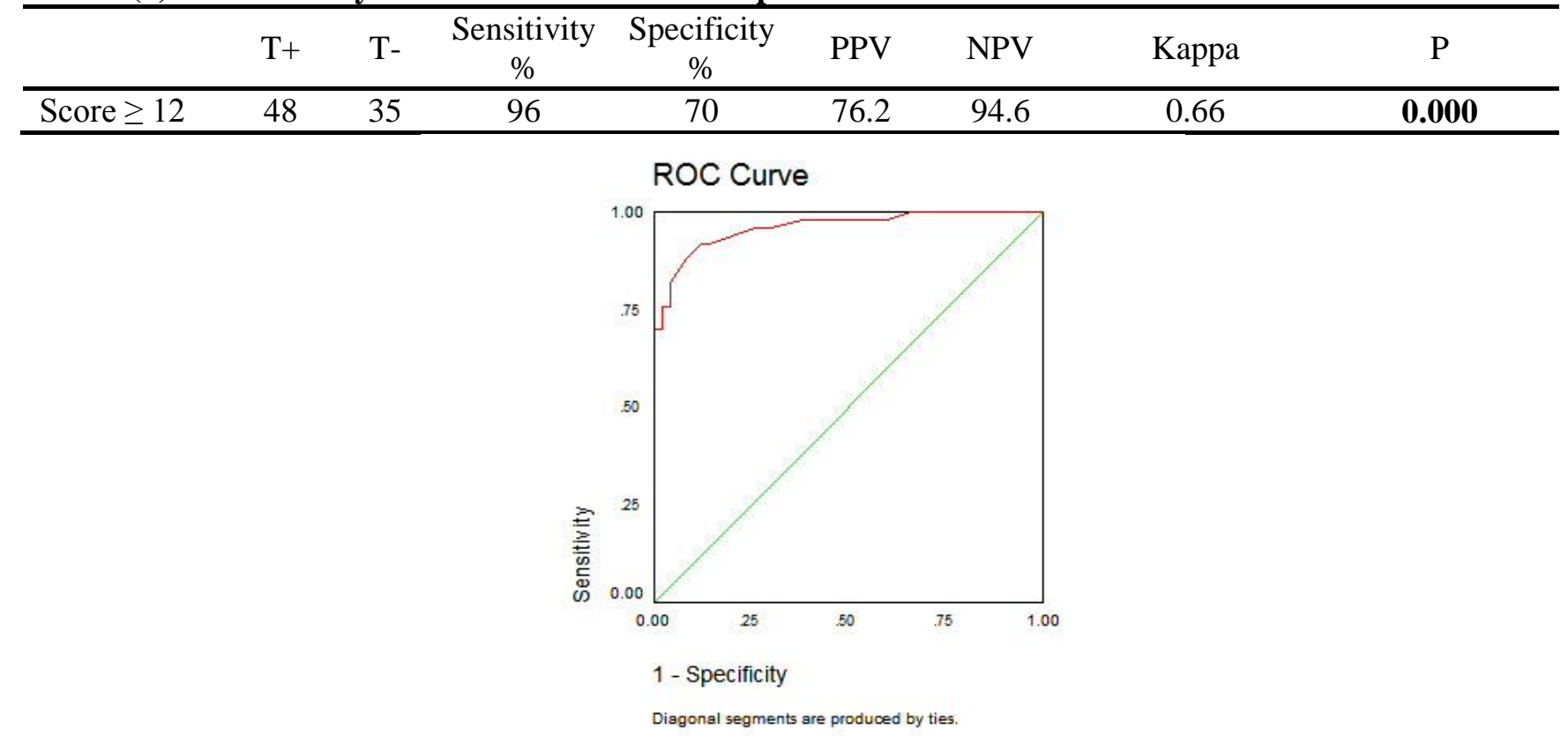

Figure (7): ROC curve for PCSF score showing sensitivity of $96 \%$ and specificity of $70 \%$ at a cut off value of $\geq 12$

\section{DISSCUSION}

In our study, there was no statistical difference betwenn the two groups regarding the age, the gender, the BMI, and hypertension. This was in agreement with (Hasan A et al, 2010) and disagree with (Hawkins B et al, 2011) where they found patients with PCSF were more males and had higher BMI, this might be contributed to the nature of the population studied with certain differences between the Japanese people and the Egyptians. This also disagree with (Gunes $Y$ et al, 2011) where they found patients with PCSF had higher BMI this might be due to increased the incidence of obesity in the Egyptians.

Regarding smoking, in our study PCSF phenomenon was more common in smokers with high statistical significant difference, this was in agreement with (Selcuk H et al, 2009) and disagree with (Gunes Y et al, 2009) and (Nurkalem Z et al, 2008) this might be because of all of those studies were conducted in Turkey which previously was a country with the highest smoking rates in the world till 2009 (The conservative media, 2009)

In our study, there was no statistical difference between both groups regarding the heart rate and blood pressure (systolic and diastolic) this was in agreement with (Selcuk $\boldsymbol{H}$ et al, 2009), (Hasan A et al, 2010) this might be due to the adequate treatment given to those patients controlling their heart rates and blood pressure.

Regarding the Canadian cardiovascular society class angina, those patients with PCSF in our study presented with higher classes this might show the aggressive nature and course of PCSF phenomenon.

In our study, the PCSF group had higher P max, $\mathrm{P}$ wave dispersion compared to the control group with significant statistical difference These was in agreement with (Gunes $Y$ et al, 2009) and 
(Mahmoud K, 2013) this might be due to altered cardiac autonomic nervous control with reduced vagal tone and a shift toward sympathetic predominance in microvessel disease.

Also patients with PCSF in our study had higher QTc min and QTc dispersion compared to the control group with significant statistical difference. This was in agreement with (Atak $R$ et al, 2003) and (Mahmoud K, 2013).

QT interval dispersion reflects regional variations in ventricular repolarization and cardiac electrical instability. Previous studies have showed that QTinterval dispersion changes during episodes of myocardial ischemia. Ischemia in microvascular level and/or altered autonomic regulation of the heart may be responsible. (Sezgin A et al, 2007).

Regarding the echo data in our study there was no statistical significant difference concerning LVEDD, LVESD, EF, E/A ratio. These results disagreed with (Gunes $Y$ et al, 2009) which show significant decrease in E/A ratio. This might be explained that most of our patients showed impaired diastolic function may be due to the prevalent obesity, hypertension among both groups.

PCSF group patients had greater LA diameter compared to the control group yet its still within the normal limits. They also showed decreased both diastolic and systolic peak flow velocities of the LAD compared to the control group with $\mathrm{P}$ values $(0.03,0.000$ and 0.000 respectively). DSPVR was lower in patients with PCSF compared to the control group with very high statistical significant difference $(\mathrm{P}$ value $=0.000)$ This was in agreement with (Nie $S$ and Wang $x$, 2010) where the PCSF phenomenon had significantly lower DPV and SPV.

There was no statistical significant difference regarding the lipid panel in either groups. This was in agreement with (Hasan A et al, 2010) and (Gunes $Y$ et al, 2011). And disagree with (Tanriverdi $\mathrm{H}$ et al, 2010) this might be due to the increased BMI in both groups in our study with abnormal lipid panels in both.

In our study, patients with PCSF had higher levels of WBCs, HCT and MPV compared to patients in the control group. This was in agreement with (Nurkalem Z et al, 2008) which showed higher MPV in PCSF group and (Yaron A et al, 2009) which showed higher HCT level in PCSF group. Both indicate increased blood viscosity in those patients with PCSF phenomenon. It is known that platelets having dense granules are more active biochemically, functionally and metabolically and are a risk factor for developing coronary thrombosis ( Nurkalem Z, 2008). Large platelets secrete high levels of prothrombogenic thromboxane A2, serotonin, beta thromboglobulin, and procoagulant membrane proteins like P-selectin and glycoprotein IIIa. In addition they are less sensitive to inhibitory effects of prostacycline on aggregation and secretion than small platelets. (Nurkalem Z, 2008)

Patients with PCSF had higher levels of HsCRP compared to the control group. This was in agreement with (Madak $N$ et al, 2010) and (Jianjun L et al, 2007) which showed increased levels of HsCRP in patients with PCSF pointing to the contribution of HsCRP as an inflammatory marker to the atherosclerotic process. That's why all patients with inflammatory diseases were excluded from our study for HsCRP to be valid as a marker for atherosclerotic process.

Regarding the troponin level, no statistical difference was found between the two groups. Perhaps because of the paucity of cases with elevated troponin making it unreliable for measuring a statistical significance.

Concerning the HbA1C. in our study, there was not statistical significant difference between both groups. This was in agreement with (Yaron $A$ et al, 2007) and disagree with (Yilmaz $M$ et al, 2010) where the whole population studied were mainly type 2 diabetics.

The PCSF score was calculated for each individual using the independent variables by the prediction equation for multiple regression (Munro $\boldsymbol{B}, 2001)$.Scoring was done for each patient in both groups using the equation giving values ranging from 2.75 to 20.92 . A cut off value $\geq 12$ was selected to identify patients with PCSF and ROC curve for that cut off value showed sensitivity of $96 \%$, specificity of $70 \%$ ( $\mathrm{P}<0.000)$. We didn't have a comparative score in the literature to validate ours, making it a new aid in predicting PCSF phenomenon where it sums up the independent non invasive variables in a figure making it easy to predict PCSF patients.

Conclusion: PCSF is associated with diabetes, greater PWD and QTc dispersion, higher HCT and HsCRP levels. The PCSF score done in our study will give an aid in predicting and PCSF patients and will help in follow up and treatment monitoring.

\section{REFERRENCES}

1. Atak $R$, Turhan $H$ and sezgin A. Effects of coronary slow flow on QT interval and 
dispersion. Ann. Noninvasive Electrocardiol. 2003;8(2):107-111.

2. Chaudhry $M$, Smith $M$, Hanna $E$ et al. Diverse Spectrum of presentation of coronary slow flow phenomenon: A consice review of the literature. Hindawi Publishing corporation. Cardiology Research and Practice. 2012:10:1-6.

3. Gibson $M$ and Zorkun C. TIMI frame count (TFC). Wikidoc; 1-11.

4. Güneş $Y$, Tuncer $M$, Güntekin $\ddot{U}$ et al. The effects of Nebivolol on $\mathrm{P}$ wave duration and dispersion in patients with coronary slow flow. Anadolu Kardiyol Derg. 2009;9:290-295.

5. Güneş $Y$, Gumrukcouglu $H$, Akdag $S$, et al. Vascular endothelial function in patients with coronary slow flow and the effects of nebivolol. Arq Bras Cardiol. 2011;97(4):275-280.

6. Hasan A, Selma A, Ercan E, et al. The effects of endothelial dysfunction and inflammation on slow coronary flow. Türk Kardiyol Dern Arş. 2010;38(5):327-333.

7. Hawkins $b$, Stavrakis $S$, Rousan $T$, et al. Coronary slow flow-Prevelance and clinical correlation. Circ J. 2012;76(4):936-42.

8. Jianjun $L$, Xuewen $Q$, Zicheng $L$ et al. Increased plasma C-reactive protein and interleukin -6 concentrations in patients with slow coronary flow. Clin/Chim Acta 2007; 385(1-2):43-47.

9. Madak N, Nazli Y, Mergen H et al. Acute phase reactants in patients with coronary slow flow phenomenon. Anadolu Kardiyol Derg. 2010; 10(5):416-420.

10. Mahmoud $K$. Effect of coronary slow flow on dispersion of P-wave \& QT- interval and its relationship with thrombolysis in myocardial infarction frame count. The Egyptian Heart Journal 2013;65:175-180.

11. Munro B. Regression. In Statistical methods for health care research. Fourth edition. Lippincott. Williams \& Wilkins. 2001; P 253.
12. Nie $S$ and Wang $X$. The coronary slow flow phenomenon: Characteristics, mechanisms and implications. Cardiovasc Diagn Ther 2011:1:3743.

13. Nurkalem Z, Alper A, Orhan A, et al. Mean platelet volume in patients with slow coronary flow and its relationship with clinical presentation. Türk Kardiyol Dern Arş. 2008;36(6):363-367.

14. Paul L, Jani D, Menete A et al, 2007. Coronary slow flow phenomenon. Cardiovasc J Afr; 18:385-386.

15. Sadamatsu K, Inoue $S$ and Tashiro H. Coronary slow flow phenomenon caused by Contrastinduced microvascular spasm. The Japanese society of internal medicine. 2007:1991-1993.

16. Selcuk H, Maden O, Selcuk $M$ et al. Documentation of impaired coronary blood flow in chronic obstructive pulmonary disease patients. Circ J. 2010 Feb;74(2):346-52.

17. Tanriverdi H, Evrengul H, Kilic D et al. Aortic pressures, stiffness and left ventricular function in coronary slow flow phenomenon. Cardiology 2010;116:261-267.

18. Turner S, 2006. The pathophysiology of the coronary slow flow phenomenon. Adelaide Research and scholarship: Thesis: Research These. http: // hdl.handle.net/2440/56182.

19. Yaron A, Efrat R, Amir $H$ et al. Determinants of slow flow in patients with normal coronary arteries. TAPAS 2009. www.emed.co.il/emed/new/usersite/presentation.

20. Yilmaz $M$, Erdem A, Yontar $O$, et al. relationship between $\mathrm{HbA} 1 \mathrm{c}$ and coronary flow rate in patients with type 2 diabetes mellitus and angiographically normal coronary arteries. Türk Kardiyol Dern Arş. 2010;38(6):405-410. 